\title{
A Novel Multicriteria Decision Making Model for Techno-Entrepreneurship
}

\author{
Üzeyir Pala ${ }^{1}$ and Salaheddine Bendak ${ }^{1^{*}}$
}

\begin{abstract}
Entrepreneurship is crucial for the survival of technology enterprises. Although the literature on techno-entrepreneurship is rich, it lacks a comprehensive and clearly structured techno-entrepreneurship management process to be followed by enterprises. It is also clear from the literature that the causal relationship between innovation, technology and entrepreneurship is complex and choosing among entrepreneurial alternatives is a multicriteria decision making problem with multiple, often conflicting, constraints. This study introduces the Integrated TechnoEntrepreneurship model that aims to help enterprises in pursuing business initiatives. The 4-stage model shows all relevant transformations of inputs from the idea generation stage until final viable product or service. Model content and face validation were done by seeking academic and industry entrepreneurship experts' opinion respectively. Validation results showed high item-total correlations for all model concepts and a high Cronbach's alpha value. It is concluded that the model is promising and potentially implementable in real life.
\end{abstract}

Keywords: Technological innovation; entrepreneurship; multicriteria decision making; competitiveness; national growth

Submitted: Jun $25^{\text {th }}, 2021 /$ Approved: August 17 $7^{\text {th }}, 2021$

\section{Introduction}

Globalisation, having become an irrevocable trend, opens new opportunities for creating jobs and economic growth. Specifically, the creation of useful and beneficial knowledge through globalisation is the main driver of innovation that fosters economic development. Findings of several studies have confirmed that globalisation has effectively promoted the overall economic growth of developing countries. Those studies attribute this growth to entrepreneurs' contribution to the economy through investing in resources to produce new products and services, creating new job opportunities, enhancing industrial activities and trade, investing in research and development, creating innovation accelerators, increasing competition that leads to better quality goods and services, improved processes and many other benefits (Gözgör \& Can, 2017; Hassan et al., 2020; Pegkasa et al., 2017; Pradhan et al., 2020; Zameer et al., 2020).

At the same time, establishing systems that support innovation and entrepreneurship is essential for securing long-term competitive edge and achieving economic advantage among nations. Specifically, techno-entrepreneurship (or technological entrepreneurship), or the formation of new enterprises to exploit technological discoveries, is an essential tool and a catalyst for the long-term economic growth and welfare of nations (Hassan et al, 2020; Liao, 2005; Zameer, 2020).

Techno-entrepreneurship is particularly essential for developing countries aiming to alleviate poverty and improve their standards of living. For those countries, encouraging innovative initiatives related to technology and opening the way for their faster implementation is expected to improve their competitiveness and benefit these countries. For this purpose, many countries aim to develop their industrial policies to encourage high value-added products and services. Initiatives all around the world use necessary finance, labour and raw materials in the course of time and transform them into new ventures in a way to yield new products and services with their human resources, know-how and innovation infrastructure. Successful entrepreneurial efforts increase, at the same time, the brand value of enterprises in the medium and long terms and open the way to national and global success through being more competitive (Bocken \& Snihur, 2020; Hassan et al., 2020; Maysami \& Elyasi, 2020; Pegkasa et al., 2017; Zameer et al., 2020).

Previous attempts have been reported in the literature to investigate means of technological innovations. For example, Becheikh and Amara (2006) did a systematic literature review to investigate technological innovations in the manufacturing sector between 1993 and 2003. The authors then proposed and discussed a framework that brought together a number of internal and contextual factors driving the innovation process. This study paved the way for other and more comprehensive studies in terms of analysing innovation indicators, dimensions, and factors.

Later, Lager (2016) evaluated efficiency improvement methods and tools in the process industry. The author concluded that that there is a need to significantly improve those methods and tools. Moreover, the author stressed on the need to come up with completely new methods and tools for better research and development (R\&D), innovation and technology management to improve company performance. However, the author purely concentrated on process industries and did not address the issues of entrepreneurship and financial resources.

The pressing need for change mentioned earlier has forced businesses to become more productive, innovative, and entrepreneurial especially in recent years. Enterprises of the 21st century are struggling to maintain their existence by trying to foresee all business processes correctly in a highly dynamic global environment. This forces businesses to continuously adopt new models to manage developments through dynamic and up-to-date strategies for continuous growth and market share maximisation. In this context, it is essential to take into consideration variations in resources and environmental conditions and adherence to the principles of continuous monitoring and improvement (Baden-Fuller \& Haefliger, 2013; Bocken \& Snihur, 2020; Pradhan et al., 2020; Zan \& Zambon, 1993).

(1) Department of Industrial Engineering, Haliç University. Sütlüce Mahallesi, İstanbul, Turkey.

* Corresponding author. Email: sbendak@halic.edu.tr

ISSN: 0718-2724. (http://jotmi.org)

Journal of Technology Management \& Innovation @ Universidad Alberto Hurtado, Facultad de Economía y Negocios. 
To highlight the importance of entrepreneurship and innovation, Müftüoğlu et al. (2013) assessed changes in GDP of all European Union countries. Results showed that $83 \%$ of the annual GDP growth is generated by sale revenues of small and medium size enterprises (SMEs). Results also showed that SMEs generate greater increase in the net value added and employment in any economy than large enterprises. A similar outcome was reported in the United States by Kaufman (2012) who found that the net new employment created by large companies in the USA between 1980 and 2005 was virtually zero. Both studies clearly showed how entrepreneurship is important for the economic growth of countries.

For the purpose of helping decision makers in techno-entrepreneurship, some researchers tried to develop a framework. For example, Pavitt (2002) introduced a technological innovation model by grouping technology management routines in three classes, 1) production of scientific and technological knowledge, 2) transformation of information into working outputs, and 3) matching of outputs with user needs. An obvious shortcoming of this grouping is that it might lead to confusion. To overcome shortcomings of Pavitt's model, Levin and Barnard (2008) added a fourth class, 4) organisational support routines, to describe technology management routines which are reported in the literature. Another improvement by Levin and Barnard (2008) was that a new and more comprehensive table of combined routines showing technology management and supporting activities was proposed. Levin and Barnard model still had shortcomings in that it did not give step-by-step directions to decision makers on technological innovation management and was not comprehensive.

Also, Shane and Venkataraman (2003) discussed the importance of developing a new techno-entrepreneurship framework where technology entrepreneurship is defined as the intersection of technology and entrepreneurship domains inside the triangle of technology, enterprise and entrepreneur. However, technology and entrepreneurship subcomponents were not considered, and the issue of financing was also missing in this study.

Similarly, Nagano at al. (2014) examined technological innovation among four national and international Brazilian firms with medium or high technological intensity. The study also introduced an integrated innovation model in the context of organisation, processes, and resources. This study also had shortcomings in that it did not include the stages and processes of entrepreneurship or the details of financing and remained only bound to the technology dimension.

Relying on lean principles and three digital multisided platform startup case studies, Ghezzi and Cavallo (2020), proposed a unified framework for digital entrepreneurship. The authors argued that lean startup approaches can be employed as agile methods to enable business model innovation in digital entrepreneurship.

All of the above mentioned studies contributed to the development of and added value to techno-entrepreneurship. They all, however, either lacked clarity in the steps (stages) to be followed, did not include the concepts that entrepreneurs should pay attention to or both.
The studies also fell short of validating their frameworks or outcomes. The current study aims to fill in this gap where it aims to introduce and validate a new and comprehensive techno-entrepreneurship model that would help entrepreneurs navigate their way through new technological innovations.

\section{Methods}

It is evident from the published peer-reviewed literature that the concept of entrepreneurial initiative effects on economic growth is still evolving and that there is a dire need to comprehensively conceptualise this causal relationship, as also postulated by Maysami and Elyasi (2020) and Çetindamar et al. (2009). It is also clear from the literature that the causal relationship between innovation, technology and entrepreneurship is rather complex and choosing among entrepreneurial alternatives is a multicriteria decision making (MCDM) problem with multiple, often conflicting, constraints.

To address the aforementioned research gap, the current study aims to introduce and validate a novel MCDM model, called Integrated Techno-Entrepreneurship (ITE) model, based on the literature published in the area and the authors personal industrial experience in the techno- entrepreneurship. This model aims to help enterprises in choosing and pursuing business initiatives within their internal and external environment and to show all relevant transformation of inputs from idea generation until the final products or services. This novel model can easily be applied to most production and service businesses.

\section{Model Development}

The ITE model is unique and novel in that it describes, for the first time, a comprehensive and detailed techno-entrepreneurship process to help enterprises from initiative creation to becoming a major player in their activity field. At the same time, it is anticipated that the model will be subject to future fine tuning and form a basis for further studies. This MCDM model is shown in Figure 1 and explained in the following subsections.

\section{Figure 1: ITE model.}

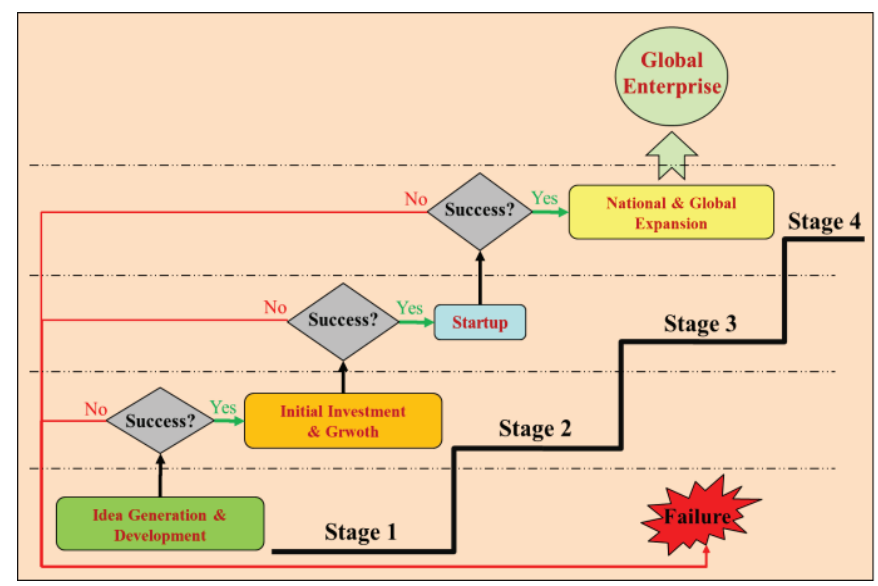




\subsection{Stage 1: Idea Generation and Development}

First stage of the model is shown in Figure 2. It describes initiating a mechanism to generate multiple potential ideas through brainstorming and an enterprise suggestion system at the beginning. Then establishing criteria to evaluate these ideas using methods, such as benchmarking, brainstorming and scoring, may be used for selecting ideas to be implemented. A suitable infrastructure (such as R\&D or Incubation Centers) can be used to design and/or develop selected ideas and transform them into physical objects by conducting activities such as calculations, design, analysis, prototyping and benchmarking. At this stage feasibility studies should also be carried out. All testing and homologation activities required for product certification and approval of prototypes according to pre-determined standards and specifications are then performed and the products are released for mass production.

Figure 2: Idea generation and development stage.

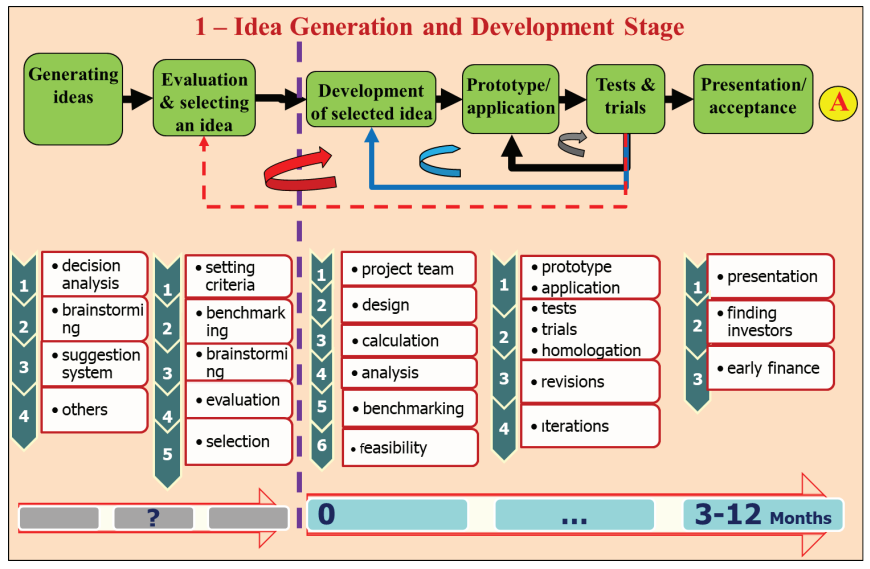

Then design-prototype-test cycle is iterated with some revisions whenever necessary until the targeted technical specifications are met. In case of service initiatives, direct implementation trials (not prototypes) shall be carried out. Product approval is granted at the end of testing and verification process and the product or service becomes ready to be launched in the market.

The final activity of the first stage involves searching and locating the most suitable early finance for mass production of the developed product or service. Then required processes should be pivoted until the right customer(s) is/are found. In other words, while validating the assumptions of the venture by customers or users, necessary revisions or changes should be made in the project and wrong assumptions should be revised according to customer feedbacks. The projected duration for this stage is typically three to twelve months but can take longer based on the needs and the sector.

\subsection{Stage 2: Initial Investment and Growth}

This stage is illustrated in Figure 3 and begins with financing where the entrepreneur tries to find an early capital from various sources such as his/her own capital, close environment, state institutions that promote and support entrepreneurship and angel investors. With such capital inflows to the enterprise, share in the partnership of the initial entrepreneur(s) will continuously decrease. After securing enough finances, a feasibility study is conducted for the first production investment, competitors are analyzed, and the location of the investment is determined through deductive logic. Also, the business organisation is completed, and the tasks are distributed after conducting the detailed feasibility study.

Figure 3: Initial investment and growth stage.

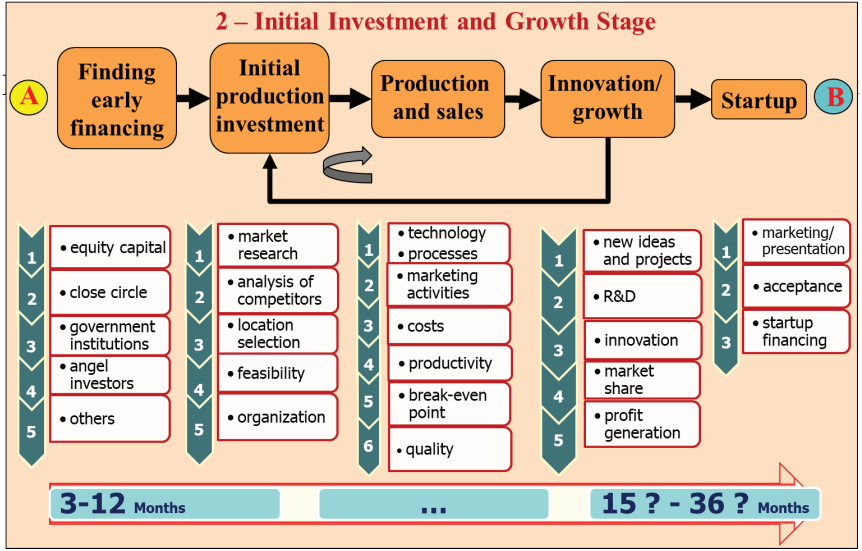

appropriate production technologies and processes, marketing activities, cost calculations and productivity improvements are carried out and the results are reviewed continuously. A break-even point must always be taken into account for every production made at this stage. It should be noted though that while the business continues to enlarge its activities, it must keep producing new ideas and projects through $\mathrm{R} \& \mathrm{D}$ activities in order to ensure its sustainability in the market. These projects should ultimately be transformed into innovations that bring more profit and growth capability to the enterprise.

After successfully reaching a certain size, the enterprise may now market itself to new and more powerful startup investors to provide necessary finance in order to grow and become a real startup. At this stage which might take 12 to 36 months, it is inevitable to make some iterations to find and develop the right products or services and increase market share.

\subsection{Stage 3: Startup}

During the startup stage, shown in Figure 4, it is essential to secure startup finance from various sources such as new partners, angel investors and venture capital. However, this new capital inflow into the enterprise will naturally require new management and organisation like previous stages and additional investments can now be put in place. For this purpose, market research, competitor analysis and feasibility studies should be carried out and the workforce should grow accordingly.

Making additional investments requires, inevitably, the selection of new technologies and processes. The aim in this respect is to reduce costs and increase productivity, market share, customer satisfaction and quality. At the same time, the company must continue developing its innovation capability. In this aspect, it is essential to continuously produce new ideas, transform some of these ideas into projects and thus make new innovations. This sequence of new ideas, projects, products/services and then investments is a continuous cycle that helps maintaining the business and achieving growth. 
As the market share, number of customers, ratio of loyal customers, brand awareness and image recognition increase in time, enterprise growth starts to reach to regional and national levels. Accordingly, the company tries to increase its market awareness and strength by creating a regional or national dealership network.

Figure 4. Startup stage.

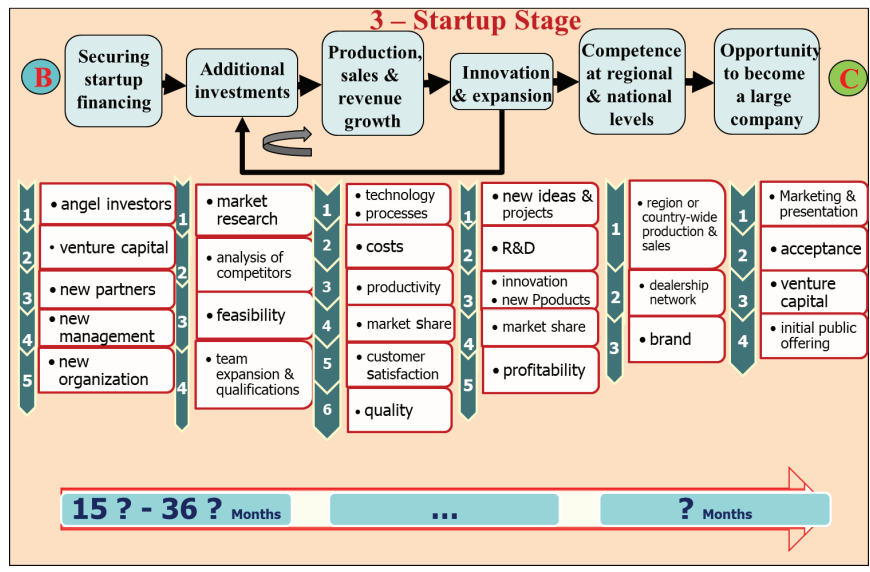

Indicators of startup stage completion include selling products or offering services at prices they deserve. The same customers can buy the same products again and recommend them to others at the same time. If these indicators exist, the company can take a new step further towards becoming a large company.

\subsection{Stage 4: National and Global Expansion}

In this fourth and last stage of the ITE model, shown in Figure 5, securing enough funding (through venture capital, private equity, public offering, new partnerships, etc.) is very critical. As is the case in previous stages, control of the company will continue to diminish with more external capital inflow. At the same time and in order to compete at national and global levels, market research, competitor analysis and feasibility studies should continuously be conducted and the workforce should be strengthened and expanded gradually depending on the needs.

Figure 5. National and global expansion stage.

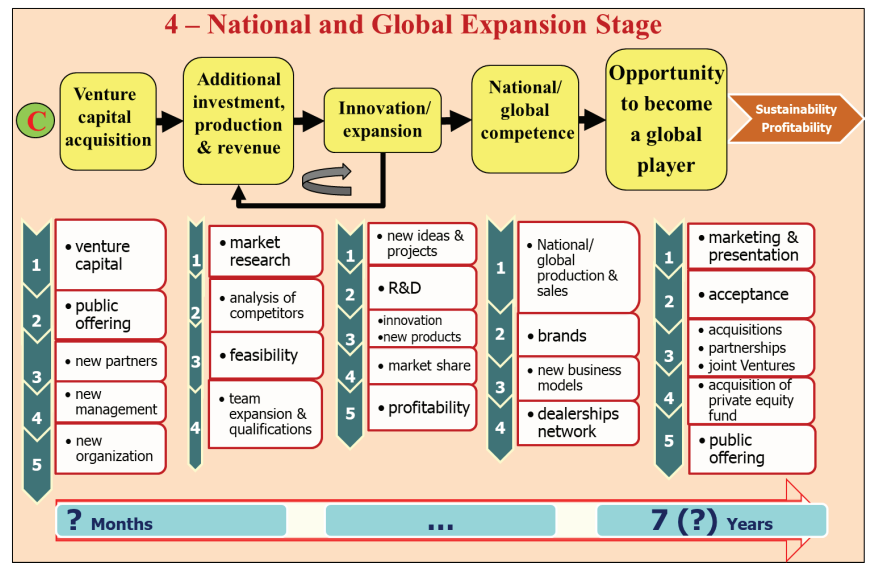

As in previous stages, new investments (based on new ideas and projects) will require new technology selections and new processes to be considered. The aim here is to carry out high quality and innovative R\&D activities to create new products and to increase market share, profitability, and customer satisfaction. Considering the current high expansion and globalisation environment, the enterprise must now be extremely specialised in strategic and tactical planning. Innovation quality, making new investments and securing new national and international markets must also be advanced to ensure sustainability of the enterprise.

As the market share, number of customers, ratio of loyal customers, brand awareness and public image increase in time, the enterprise starts to reach national and possibly global levels. Accordingly, the company should try to increase its market awareness and strength by creating a strong dealership network. With a visionary strategic management approach, enterprises that foresee and understand the future better will survive, and those who cannot keep up with time and conditions will disappear.

\section{Model Validation}

Model validation is required for any newly developed model to ensure its comprehensiveness and cohesion. Netemeyer et al. (2003) suggested that all items and dimensions of a model should be reviewed and validated for representativeness by expert judges. At the same time, it is also essential to do both content and face validity. Content validity is defined as the degree to which items are representative of the concepts of interest (Haynes et al., 1995). Such content validity is usually verified by asking experts in the academic field. Face validity, which usually follows content validity, is done to check if model items appear to be valid, in addition to being valid content wise (Nevo, 1995). Netemeyer et al. (2003) recommended asking experts with long industrial experience to ensure face validity of any model. The number of experts whose opinion is sought might range, according to their scarcity, between one and ten or even more (see Bendak et al. (2020), Cheaitou et al. (2019) and Li et al. (2015) for example).

In the current study, ten experts were asked to examine the taxonomy of items that form the basis of the ITE model. The opinion of five academics was sought to do content validity and five entrepreneurs to do face validity. The five academics (three with $\mathrm{PhD}$ degrees in engineering, one with $\mathrm{PhD}$ degree in health sciences and one with $\mathrm{PhD}$ degree in management) whose opinion was sought to do content validity were established academics with several peerreviewed publications and nine years average experience in teaching techno-entrepreneurship and management of technology courses. The five experts from industry (two with $\mathrm{PhD}$ degrees in engineering, two with MSc in engineering and with MSc in finance) chosen to do the face validity were established entrepreneurs with an average experience in technology related industries of 27 years. Those ten experts came from five different countries (Australia, Sudan, Turkey, UAE, and UK). 
Likert scale is usually used in similar evaluations as it gives an opportunity to capture the attitude and opinion of respondents (DeVellis, 2003). In evaluating the ITE model, academic experts were asked to evaluate items of the model, as given in Table 1, using a 7-point Likert scale ranging from 1 (strongly disagree) to 7 (strongly agree). In addition, they were asked two open ended questions. The first open-ended question asked experts if there were any missing vital items that need to be added to the questionnaire and the second asked them if they had any comments or suggestions. It should be noted that the original set of questions did not ask the experts to rate the model's time range (item 6). However, and based on the feedback of the first academic whose opinion was sought, this question was added to the questionnaire and asked to all other nine experts as well.

Table 1: Questions asked to all experts.

\begin{tabular}{|c|c|c|}
\hline Ques. No. & Questions & Response \\
\hline \multirow{8}{*}{ Question 1} & Rate the following items ( 1 = strongly disagree; 7 = strongly agree $)$ & Rate (1-7) \\
\hline & Item 1: The model is implementable in real life. & \\
\hline & Item 2: Stage 1 of the model demonstrates all important factors to be considered in generating and developing innovative technological ideas. & \\
\hline & Item 3: Stage 2 of the model identifies all important elements to be considered in securing initial investment and growing the ideas. & \\
\hline & Item 4: Stage 3 of the model lists all startup issues to be considered. & \\
\hline & Item 5: Stage 4 of the model shows all activities on national and global expansion that should be performed. & \\
\hline & Item 6: The suggested time range for the four stages in the model is realistic and can be implemented in most cases. & \\
\hline & Item 7: The ITE model is comprehensive and represents the main aspects of innovative techno-entrepreneurship in an integrated form. & \\
\hline Question 2 & In your opinion, are there any missing vital items that need to be added to the model in addition to the above items? If yes, please write them. & $\ldots \ldots+\cdots \cdots \cdots$ \\
\hline Question 3 & Do you have any suggestions or comments on the model? & n.............. \\
\hline
\end{tabular}

Then, the questionnaire was used to seek the opinion of industrial entrepreneurs. All ten experts were contacted by phone and the objective of the model was explained to them. Then they were asked to respond to the questions.

On top of checking validity of the model, it is essential to check its reliability. In the current study, reliability is checked by two methods: Model's Cronbach's alpha value and item-total correlations (Cronbach, 1951). Nunnally and Bernstein (1994) and DeVellis (2003) suggested that Cronbach's alpha value should be 0.7 or greater for the model to be considered reliable. There is also no single agreed-upon method to judge the strength of item-total correlations so previously published studies (like Bendak et al. (2020) and DeVellis (2003) for example) were taken as references. It was assumed in the current study that all item averages $\geq 4.5$ (out of 7 ) would indicate item validity and that an item-total correlation $\geq 0.5$ would indicate an acceptable item.

Mean and standard deviation of all responses are given in Table 2 for both academic and industrial experts. Item-total correlations of the four stages of the model are also given. The model's Cronbach's alpha value was found to be equal to 0.723 before minor improvements according to feedbacks from academicians and industrial experts.
Table 2: Model validation outcomes.

\begin{tabular}{l|l|l|l|l}
\hline Item & $\begin{array}{l}\text { Mean of acad. } \\
\text { expert respon- } \\
\text { ses (std dev) }\end{array}$ & $\begin{array}{l}\text { Mean of ind. expert } \\
\text { responses (std dev) }\end{array}$ & $\begin{array}{l}\text { Overall } \\
\text { Mean }\end{array}$ & $\begin{array}{l}\text { Item-Total } \\
\text { correlation }\end{array}$ \\
\hline 1 & $6.2(0.84)$ & $6(0.71)$ & 6.1 & N/A \\
\hline 2 & $5.8(0.84)$ & $5.4(0.55)$ & 5.6 & 0.61 \\
\hline 3 & $6.2(0.45)$ & $5.8(0.45)$ & 6 & 0.54 \\
\hline 4 & $6(0.71)$ & $5.8(0.45)$ & 5.9 & 0.66 \\
\hline 5 & $6.2(0.84)$ & $5.4(0.55)$ & 5.8 & 0.52 \\
\hline 6 & $5(1.58)$ & $5.6(0.55)$ & 5.3 & N/A \\
\hline 7 & $6.4(0.55)$ & $6(0)$ & 6.2 & N/A \\
\hline
\end{tabular}

It is clear from model validation results given in Table 2 that the mean response of all items in both expert groups varied between 5 and 6.4 indicating that the model is valid, implementable and comprehensive. At the same time, the Cronbach's alpha value of 0.723 indicates that the model is valid and internally consistent.

It should be noted though that this Cronbach's alpha value of 0.723 is based on the original ITE model before seeking the opinion of experts. As some experts suggested adding a few concepts to the model that they thought were missing (where quality was the most frequent and striking example), the model was slightly changed to incorporate these suggestions. It is anticipated that this Cronbach's alpha value of 
0.723 would be even greater after incorporating the few suggestions put forward by the experts. It should be also noted that the model given in the previous subsections represented the final version of the model after incorporating those few suggestions by the experts.

\section{Discussion and Conclusions}

Techno-entrepreneurial processes can often be quite ambiguous and cumbersome due to the very large number of factors that affect such processes. There is a strong need for an integrated road map that will enable an emerging enterprise to see the big picture both internally and externally from the idea stage until being a global business. This need is particularly critical for innovative technology projects that go through highly complex design, prototyping, testing and validation processes. Therefore, a holistic and detailed model, called Integrated Techno-Entrepreneurship (ITE) model, is proposed in the current study based on the literature and expertise of the authors in this area. Then the model is validated by academic and industry experts in the techno-entrepreneurship area.

The integrated road map proposed in the ITE model can be useful for new and experienced individual entrepreneurs as well as for corporate enterprises. The model can help first time entrepreneurs as it gives them an insight of the entrepreneurial process and draws a road map for them. The model can also help experienced individual and corporate entrepreneurs as they might experience extreme difficulty in dealing with the numerous factors interacting with their initiatives. This ITE model can help them navigate their way through their entrepreneurial journey and enable them to see the whole picture.

Since the ITE model is based on the models, factors and ideas reported in the published peer-reviewed literature and the authors own experience in this area, it can help entrepreneurs avoid missing important steps. It might also serve as a road map and a checklist for them which will help them in being consistent and saving time. It can also help in facilitating strategic and tactical decision-making processes. This will in turn bring economic gain and even develop business awareness and vision.

It should be stressed here, and as was also indicated by Baden-Fuller and Haefliger (2013), that the ITE model proposed in the current study represents a decision-making tool that can be used by company management. However and due to market dynamics and the unique identity and circumstances of every company, the ITE model and similar models should not be followed blindly. Creativity and progressive and passionate approach for continuous development should govern this following of the proposed model. At the same time and as this model is unique in its comprehensiveness and approach, it cannot be considered complete, perfect, and final, especially with the continuously changing customer preferences and demand on goods and services. This makes the need to continuously develop, enhance and update the model inevitable. This can be done in future studies.

\section{References}

Becheikh, N.L., \& Amara, R.N. (2006). Lessons from innovation empirical studies in the manufacturing sector: A systematic review of the literature from 1993-2003. Technovation, 26, 644-664. https://doi. org/10.1016/j.technovation.2005.06.016

Bendak, S., Shikhli, A.M., \& Abdel-Razek, R.H. (2020). How changing organizational culture can enhance innovation: Development of the innovative culture enhancement framework. Cogent Business \& Management, 7: 1712125, 1-17. https://doi.org/10.1080/23311975.2020.1712125

Bocken, N., \& Snihur, Y. (2020). Lean startup and the business model: Experimenting for novelty and impact. Long Range Planning, 53, 101953. https://doi.org/10.1016/j.lrp.2019.101953

Çetindamar, D., Phaal, R., \& Probert, D. (2009). Understanding technology management as a dynamic capability: A framework for technology management activities, Technovation, 29, 237-246. https://doi. org/10.1016/j.technovation.2008.10.004

Cheaitou, A., Larbi, R., \& Al Housani, B. (2019). Decision making framework for tender evaluation and contractor selection in public organizations with risk considerations. Socio-Economic Planning Sciences, 68 ,100620, 1-12. https://doi.org/10.1016/j.seps.2018.02.007

DeVellis, R.F. (2003). Scale Development: Theory and Applications, 2nd ed., Sage, Thousand Oaks, CA.

Ghezzi, A., \& Kavallo, A. (2020). Agile Business Model Innovation in Digital Entrepreneurship: Lean Startup Approaches. Journal of Business Research, 110, 519-537. https://doi.org/10.1016/j.jbusres.2018.06.013

Gözgör, G., \& Can, M. (2017). Causal Linkages among the Product Diversification of Exports, Economic Globalization and Economic Growth. Review of Development Economics, 21(3), 888-908. https:// DOI:10.1111/rode.12301

Hassan, M.S., Bukhari, S., \& Arshed, N. (2020). Competitiveness, governance and globalization: what matters for poverty alleviation? Environment, Development and Sustainability, 22, 3491-3518. https:// doi.org/10.1007/s10668-019-00355-y

Kaufman, B.E. (2012). Strategic Human Resource Management Research in the United States: A Failing Grade after 30 Years. Academy of Management Perspectives, 26(2), 12-36. http://dx.doi.org/10.5465/ amp.2012.0037

Lager, T. (2016). Managing Innovation \& Technology in the Process Industries: Current practices and future perspectives. Procedia Engineering, 138, 459-471. http://doi: 10.1016/j.proeng.2016.02.105

Levin, D.Z., \& Barnard, H. (2008). Technology management routines that matter technology managers. International Journal of Technology Management, 41(1-2), 22-37. 
Li, Z., Shen, W., Xu, J., \& Lev, B. (2015). Bilevel and multi-objective dynamic construction site layout and security planning. Automation in Construction, 57, 1-16. https://doi.org/10.1016/j.autcon.2015.04.011

Liao, S. (2005). Technology management methodologies and applications: A literature review from 1995 to 2003. Technovation, 25, 381393. https://doi.org/10.1016/j.technovation.2003.08.002

Maysami, A.M., \& Elyasi, G.M. (2020). Designing the framework of technological entrepreneurship ecosystem: A grounded theory approach in the context of Iran. Technology in Society, 63, 101372, 1-14. https://doi.org/10.1016/j.techsoc.2020.101372

Müftüoğlu, T., Ürper, Y., Başar, M., \& Tosunoğlu, B.T., 2013. Entrepreneurship (in Turkish), Anadolu University Publication no: 1567.

Nagano, M.S., Stefanovitz, J.P., \& Vick, T.e. (2014). Innovation management processes, their internal organizational elements and contextual factors: An investigation in Brazil. Journal of Engineering and Technology Management, 33, 63-92. https://doi.org/10.1016/j. jengtecman.2014.02.004

Netemeyer, R.G., Bearden, W.O., \& Sharma, S. (2003). Scaling Procedures: Issues and Applications, Sage, Thousand Oaks, CA.

Nevo, B. (1995). Face validity revisited. Journal of Educational Measurement, 22(4), 287-93.

Nunnally, J.C., \& Bernstein, I.H. (1994), Psychometric Theory, 3rd ed., McGraw-Hill, NewYork, NY.
Pavitt, K. (2002). Innovating routines in the business firm: What corporate tasks should they be accomplishing? Industrial and Corporate Change, 11, 117-123.

Pegkasa, P., Staikourasb, C., \& Tsamadiasca, C. (2019). Does research and development expenditure impact innovation? Evidence from the European Union countries. Journal of Policy Modeling, 41(5), 10051025. https://doi.org/10.1016/j.jpolmod.2019.07.001

Pradhan, R.P., Arvin, M.B., Nair, M., \& Bennett, S.E. (2020). The dynamics among entrepreneurship, innovation, and economic growth in the Eurozone countries. Journal of Policy Modeling, 42, 1106-1122. https://doi.org/10.1016/j.jpolmod.2020.01.004

Shane, S., \& Venkataraman, S. (2003). Guest editors' introduction to the special issue on technology entrepreneurship. Research Policy, 32, 181-184. https://doi.org/10.1016/S0048-7333(02)00104-X

Zan, L., \& Zambon, S., 1993. Strategic change and the strategic approach: Making sense in process. In Zan, L., Zambon, S., and Pettigrew, A.M. (eds.), Perspectives on Strategic Change, Norwell, MA, Kluwer Academic Publishers, 1, 1-34.

Zameer, H., Shahbaz, M., \& Vo, X.V. (2020). Reinforcing poverty alleviation efficiency through technological innovation, globalization, and financial development. Technological Forecasting and Social Change, 161, 120326, 1-10. https://doi.org/10.1016/j.techfore.2020.120326 
